\title{
DO BALÃO PARA A LINHA: AS HISTÓRIAS EM QUADRINHOS COMO MODELO DE TRADUÇÃO DO DIÁLOGO NA LITERATURA INFANTOJUVENIL
}

\section{OUTSIDE THE SPEECH BUBBLE: COMICS AS A MODEL FOR DIALOGUE TRANSLATION IN CHILDREN'S LITERATURE}

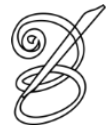 \\ Gustavo Henrique Santos BRUNETTI* \\ Centro Universitário das Faculdades Metropolitanas Unidas, Brasil
}

\begin{abstract}
Resumo: A literatura e as histórias em quadrinhos (HQs) são linguagem distintas, mas têm pontos em comum. Este trabalho tem como foco um deles: o diálogo. Apresentam-se alguns aspectos da linguagem das HQs no que tange às falas, seu caráter oral e as tendências de seu uso no português brasileiro. Sugere-se que a interseção desses aspectos corresponde a uma série de propostas defendidas por Britto (2012) a respeito do efeito de oralidade da tradução de diálogos na ficção literária. Por fim, propõe-se que as HQs da Turma da Mônica podem servir de modelo para a tradução de diálogos na literatura infantojuvenil.
\end{abstract}

Palavras-chave: Histórias em quadrinhos. Diálogo. Oralidade. Literatura infantojuvenil.

Abstract: Literature and comics are different languages, but they share some features. This paper focuses on one of them, namely dialogue. We present some aspects of the language of comics in relation to dialogue, its oral character, and an interesting trend in its use in Brazilian Portuguese. We suggest that the intersection of these aspects corresponds to a number of proposals defended by Britto (2012) regarding the orality effect of dialogue translation in literary fiction. Finally, we propose that Monica's Gang comics may serve as a model for dialogue translation in children's literature.

Keywords: Comics. Dialogue. Orality. Children's literature.

RECEBIDO EM: 3 de janeiro de 2019

ACEITO EM: 5 de abril de 2019

PUBLICADO EM: julho 2019 


\section{Introdução}

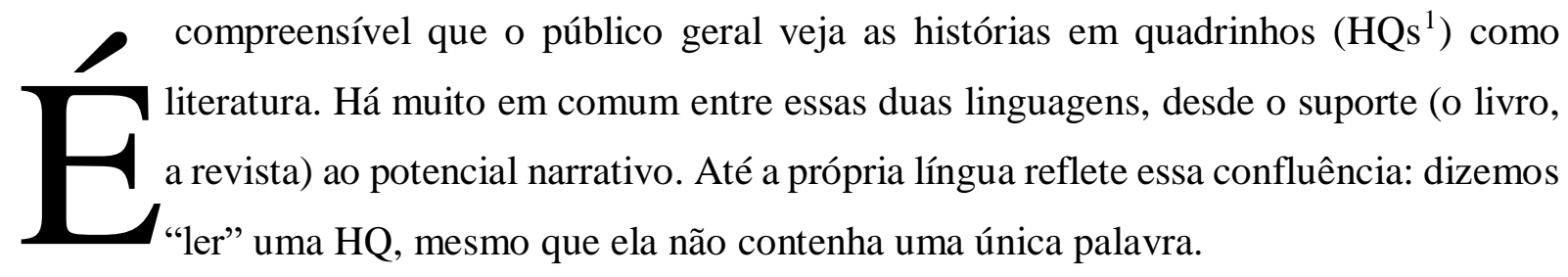

As HQs também se aproveitaram dessa concepção para ganhar certo prestígio. Se até hoje muitos acham que se trata de algo para crianças, durante pelo menos três quartos do século XX a reputação das HQs era muito pior. Parte do que reverteu essa situação foi a introdução das graphic novels ${ }^{2}$ nas livrarias. Também foi significativo que a HQ Watchmen tenha sido incluída na lista dos romances mais relevantes do século XX da revista Time (GROSSMAN; LACAYO, 2005).

Entretanto, como argumenta Ramos (2012, p. 17): Quadrinhos são quadrinhos. E, como tais, gozam de uma linguagem autônoma, que usa mecanismos próprios para representar os elementos narrativos. Há muitos pontos comuns com a literatura, evidentemente. Assim como há também com o cinema, o teatro e tantas outras linguagens. ${ }^{3}$

De fato, a linguagem das HQs está mais próxima de outras linguagens visuais, com a diferença do número de dimensões trabalhadas: o desafio da pintura e da fotografia é expressar três dimensões em um suporte que tem duas; o cinema faz o mesmo, mas introduz a quarta dimensão (o tempo) por meio do uso de imagens em sequência; já as HQs impõem o desafio de expressar as quatro dimensões utilizando duas. A vinheta é mais que o registro de um momento; ela sugere um recorte no tempo, que pode ser curtíssimo ou durar muito. Podemos ver esse fenômeno na seguinte vinheta:

Figura 1

Fonte: Ditko (1964)

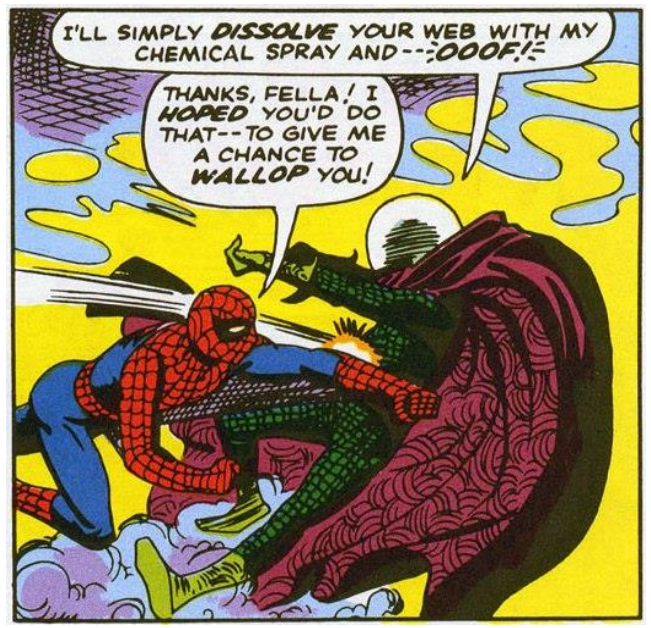


Na vinheta da figura 1 acima, há uma sucessão de, ao menos, quatro eventos: 1) Mysterio diz que vai dissolver a teia com o spray químico; 2) Homem-Aranha atinge Mysterio com um soco; 3) Mysterio reage ao soco (ooof!); e 4) Homem-Aranha diz que esperava justamente essa ação para que pudesse atingir Mysterio.

Explicando tal fenômeno, McCloud (1994, p. 96) argumenta que "nossos olhos foram bem treinados pela fotografia e pela arte figurativa para ver qualquer imagem contínua com um único instante no tempo" ${ }^{4}$, e que "se o som é introduzido, isso deixa de ser verdade" 5 (MCCLOUD, 1994, p. 98). A fala na vinheta acima realmente alonga o tempo do quadrinho, mas a imagem por si só também sugere um tempo maior, pois há linhas de movimento que indicam o percurso do punho esquerdo do herói.

Se as HQs diferem das outras artes visuais, a distância é ainda maior da literatura, uma vez que esta não usa a imagem como recurso de linguagem. A prova dos nove de que são duas linguagens diferentes: é perfeitamente possível escrever uma HQ sem palavras, mas não um texto literário. Existem muitos esforços recentes por parte dos estudiosos de HQs para distanciar as duas linguagens, a fim de solidificar a autonomia da nona arte.

Sendo linguagens diferentes, traduzi-las envolve critérios e processos diferentes, evidentemente. No entanto, naquilo que as linguagens têm em comum, é possível aproveitar ideias de estudiosos da tradução literária e levá-las à tradução de HQs, assim como se pode espelhar no que já é feito nas HQs para fazer tradução literária.

Neste trabalho, nosso objetivo é realçar a importância de uma dessas ideias, com foco sobre um desses pontos em comum: os diálogos. Primeiro, vemos o que Britto (2012) propõe acerca da tradução de diálogos na prosa. Então, discorremos sobre algumas características da linguagem e da tradução das HQs. Em seguida, examinamos a função que, nas HQs, os diálogos assumem. Depois, descrevemos uma tendência das HQs publicadas no Brasil, tanto as traduzidas quanto as originalmente escritas em português para, enfim, apresentarmos o que consideramos um modelo para a tradução de diálogos para a literatura infantil: as HQs da Turma da Mônica.

\section{Algumas proposições de Britto}

Paulo Henriques Britto apresenta em A tradução literária algumas técnicas que, segundo ele, levam a "escrever diálogos que proporcionem ao leitor um certo efeito de verossimilhança" (BRITTO, 2012, p. 86). Para ele, uma conversa natural causa estranheza quando transcrita no papel, portanto o "trabalho do ficcionista e do tradutor de ficção é criar 
artificialmente - através dos recursos da arte de escrever diálogos - a impressão de que o que se está lendo é a fala real de um personagem (BRITTO, 2012, p. 87).

É um equilíbrio delicado, pois "o diálogo não deve se afastar demasiadamente de algumas convenções da linguagem escrita", uma vez que o texto será lido, porém “[...] não deve se ater demais a elas, a ponto de fazer com que o leitor reaja tal como reagi [...] ao me deparar com um Huckleberry Finn falando um português tão impecável quanto o de Jânio Quadros.” Esse efeito é atingido quando se usam "marcas de oralidade" (BRITTO, 2012, p. 87).

Brito divide essas marcas em fonéticas, lexicais e morfossintáticas. A respeito das primeiras, afirma que só "pra" (no lugar de "para") e "né” são amplamente usados na ficção brasileira, e por isso desaconselha o uso de outras marcas desse tipo em traduções.

Quanto a marcas lexicais, o autor diferencia coloquialismos de gírias: estas, na sua definição (que ele próprio reconhece que é de certo modo restrita), são usadas por um grupo bastante específico e são efêmeras; quando "passam a ser usadas por toda a população", viram coloquialismos. Um exemplo é a palavra "legal" no sentido de "bom". Britto não recomenda o uso de gírias, e, quando o tradutor as usa, "precisa estar consciente do fato de que sua tradução corre o risco de ficar datada mais cedo" (BRITTO, 2012, p. 94); contudo, acha seguro o uso de coloquialismos para produzir o efeito de verossimilhança.

Já as marcas morfossintáticas são consideradas pelo autor como as melhores, pois variam pouco entre as regiões do Brasil. Entre elas, destaca inicialmente a o uso de pronomes átonos em início de frase, de pronomes retos como objeto ("xingar ele", por exemplo) e de expressões como "que nem".

Outro tipo de marca morfossintática que Britto propõe traz problemas para o tradutor de HQs, mas é inevitável. O português brasileiro falado tende a usar o futuro do presente e os pretéritos imperfeito e mais-que-perfeito nas formas analíticas (como observou Lauand em estudo que será citado abaixo) e também explicitar o sujeito mesmo quando ele é redundante (especialmente "eu"). Isso dificulta de certa forma o trabalho do tradutor porque aumenta consideravelmente o número de caracteres e aumenta o risco de o texto não caber no balão, como será detalhado na seção 3 .

Britto apresenta também o "uso de artigo definido antes de nomes próprios", o "uso de singular para se referir a um par", a "dupla negativa", entre outros mais específicos, sem pretensão de esgotar as possibilidades. $\mathrm{O}$ autor salienta que a marca não pode causar estranheza, pois "a boa marca de oralidade é aquela que provoca um efeito de verossimilhança sem chamar demais a atenção para si própria” (BRITTO, 2012, p. 101). 
Na obra em questão, Britto não aborda a questão da tradução de literatura infantojuvenil, mas o diálogo é parte importante desse tipo de literatura. Aliado a isso, há o fato de que a naturalidade dos diálogos pode coibir estranhezas que o jovem leitor possa sentir durante a leitura. Portanto, consideramos que as propostas de Britto são especialmente valiosas nessa literatura.

\title{
2 A tradução de HQs
}

As HQs têm dois elementos constitutivos principais: a imagem e o texto. De acordo com Eisner (1985, p. 122):

\begin{abstract}
Quando se escreve com palavras apenas, o autor direciona a imaginação do leitor. Nas HQs, o imaginar já está feito para o leitor. Uma imagem, uma vez desenhada, passa a ser uma declaração precisa que permite pouca ou nenhuma interpretação a mais. Quando os dois são "misturados", as palavras tornam-se fundidas às imagens e não servem mais para descrever, mas sim para fornecer som, diálogo e passagens de ligação. ${ }^{6}$
\end{abstract}

Ou seja, imagem e palavra são indissolúveis na linguagem das HQs. Não se trata de uma imagem que ilustra o texto ou um texto que explique a imagem, e sim dos dois em relação simbiótica, embora, ainda segundo Eisner, as HQs sejam "primariamente visuais" (EISNER, 1985 , p. 123$)^{7}$

Neste artigo, seguiremos a estratégia proposta por Tomášek para análise dos elementos constitutivos. O autor faz distinção entre "texto", que se refere à parte escrita das HQs, e "discurso", que engloba as ilustrações, painéis e também o texto, ou seja, todos os elementos da linguagem dos quadrinhos (TOMÁŠEK, 2009, p. 32). É importante salientar que o texto faz parte do discurso, uma vez que muitas vezes as próprias letras têm valor expressivo. No exemplo da figura 2, o balão da vinheta do meio tem letras maiores que as dos outros, o que indica que o tom de voz foi mais alto.

Figura 2
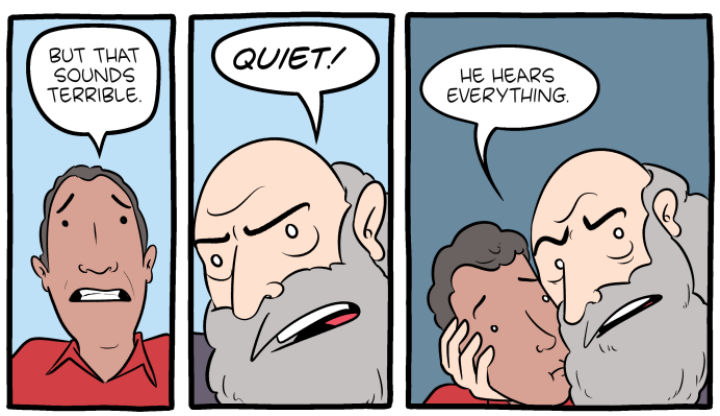

Fonte: Weinersmith (2018) 
Ou na figura 3, em que a fonte da letra reforça o tipo de voz que tem a personagem.

Figura 3

Fonte: Gurewitch (sem data).

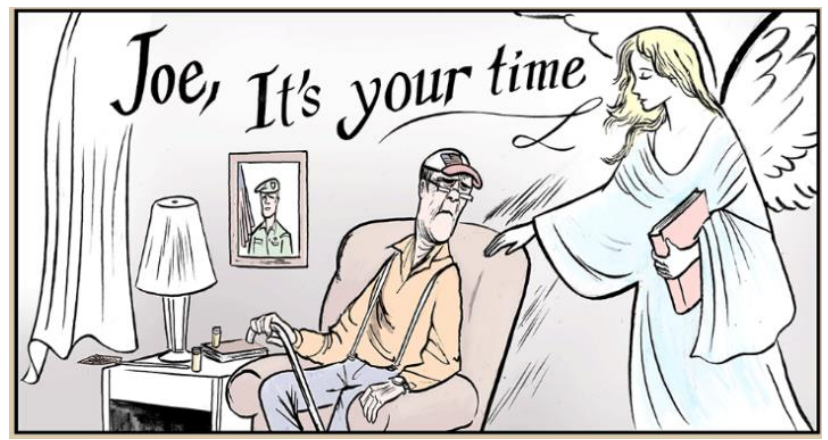

Outro modo de expressividade exclusivo das HQs é o próprio balão. Existem as formas bastante difundidas, como o balão de fala e o balão de pensamento, mas existem infinitas possibilidades que fogem do padrão e atribuem outra camada de significado à fala. Vejamos o exemplo da figura 4:

Figura 4

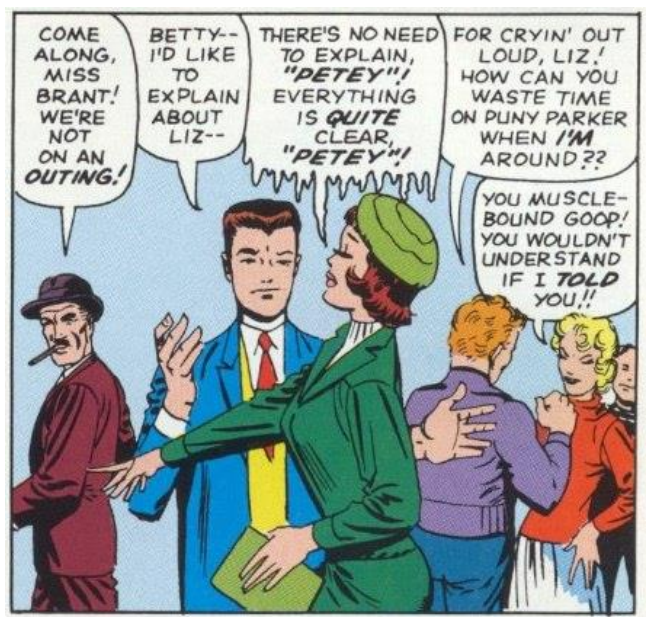

Fonte: Ditko (1964)

O balão do meio é diferente dos outros, comunicando a frieza com que a personagem fala com o namorado. Com as mesmas palavras, mas um balão diferente, seria possível fazer com que ela expressasse raiva, tristeza ou qualquer outra emoção que o artista fosse capaz de desenhar.

Esses recursos não fazem parte do texto em si, e sim do discurso. Essa dinâmica entre texto e discurso faz com que, de certa forma, o tradutor de HQ tenha, em relação ao literário, menos liberdade para trabalhar, pois 
[...] a literatura, diferentemente das HQs, não contém unidades intraduzíveis [...], e não há limitações que impeçam o tradutor de modificar o texto. Por outro lado, o tradutor de HQ é limitado pelo tamanho da legenda ou do balão (eles podem ser modificados para acomodar o texto, mas a modificação pode ser executada apenas até certo ponto, do contrário o balão ou a legenda sobrepor-se-ia à imagem). (TOMÁŠEK, 2009, p.31). ${ }^{8}$

Ou seja, o texto literário é mais "maleável” para tradução, em relação à HQ, pois pode ser expandido para acomodar explicações e referências que não seriam óbvias para o leitor de outra cultura. Além disso, o tradutor de HQs tem que contornar elementos textuais que fazem parte da construção da imagem (que são as "unidades intraduzíveis" de Tomášek). Vemos esse caso na figura 5 :

Figura 5

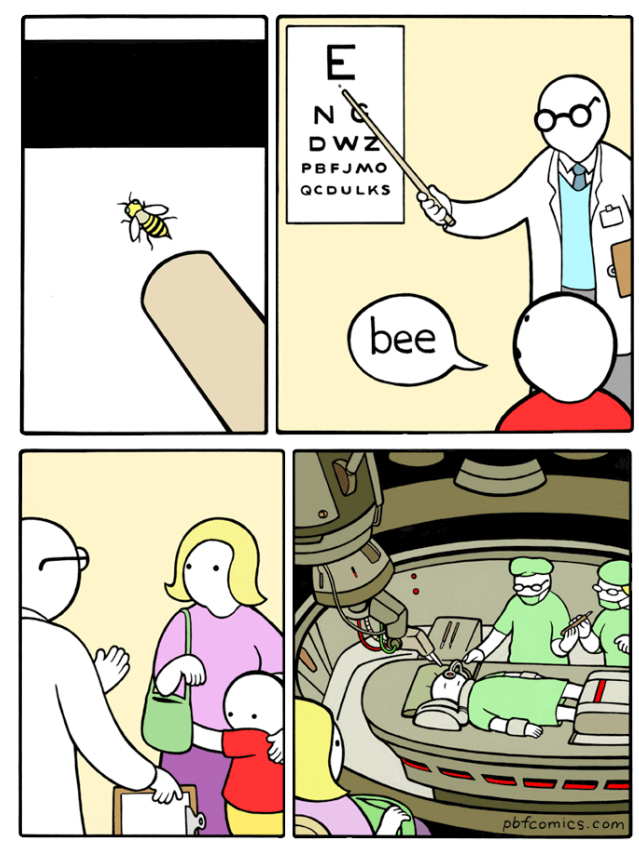

Fonte: Gurewitch (sem data)

A princípio, seria muito simples traduzir uma palavra que tem um equivalente bastante direto em português: bee = abelha. No entanto, todo o discurso da HQ faz com que a tradução direta tire o sentido, e a piada se perca. O tradutor, portanto, só tem a liberdade de traduzir o texto, mas deve se atentar ao discurso.

Considerando as propostas de Tomášek, Assis (2016, p. 26) propõe cinco especificidades da tradução de HQs, que a fazem diferente da tradução de outros tipos de texto, sobretudo a prosa:

a) Ingerência do tradutor reduzida às unidades de material linguístico, ou seja, cabe ao tradutor manipular apenas a parte linguística do texto, e não as imagens; 
b) Indissolubilidade da mancha gráfica, pois o espaço da mancha gráfica ocupado pelo texto original deve ser similar ao do texto original;

c) Indissolubilidade das quebras verbais, uma vez que a tradução deve seguir os segmentos dos balões originais, especialmente quando uma fala é dividida entre vários balões;

d) Documento de tradução = roteiro para letreirista, o que vale dizer que o que o tradutor envia para a editora pode sofrer uma série de alterações para que o letreirista consiga inserir o texto adequadamente, e o texto publicado pode não ser exatamente aquele que o tradutor sugeriu; e

e) O letreirista como cotradutor, consequência da especificidade anterior, pois a responsabilidade pelo texto traduzido é compartilhada pelos dois profissionais.

A especificidade $a$ é a mais relevante para a tradução da HQ acima. Qualquer que seja a solução encontrada pelo tradutor, ele precisaria da ajuda do letreirista ou mesmo do ilustrador para mudar algum elemento gráfico (a abelha ou a letra para a qual o médico aponta, por exemplo). Se a mudança não puder ser feita por questões técnicas ou legais, não há o que o tradutor possa fazer a não ser tentar encontrar outra tradução.

Portanto, ao tradutor de HQs são impostos limites e restrições específicas que o tradutor literário, em geral, não enfrenta.

\section{O diálogo nas HQs}

Há o que parece ser um consenso entre os estudiosos: o texto dos balões nas HQs é fala $^{9}$. Não se trata de língua escrita, mas sim uma representação escrita da língua falada, o que vai ao encontro do que Britto propõe. Sendo assim, são muito comuns as marcas de oralidade nos diálogos das HQs.

Na figura 1 acima, podemos ver ao menos duas delas: em nível vocabular, temos a palavra "fella", cuja grafia tenta recuperar certa forma de se pronunciar a palavra "fellow" (algo como "colega"); e em nível sintático, temos o travessão juntando duas frases que não estão articuladas rigorosamente, mas de maneira bastante natural para uma fala.

Como representações das falas, "o conteúdo dos balões ajuda os autores a trabalhar as características dos personagens. A escolha do vocabulário é um dos principais recursos" (RAMOS, 2012, p. 60). A fala ajuda a revelar o personagem e, portanto, deve condizer com ele. Outra função dos diálogos é dar ritmo à narrativa: 
O texto verbal, como tal, tem uma duração: as palavras são pronunciadas no tempo, duram um certo tempo. Assim, a duração das palavras é representada na imagem por meio da representação das palavras. A imagem dura (ao menos) tanto quanto as palavras contidas nela. (BARBIERI, 2017, p. 214).

Barbieri mostra como a ausência de diálogos faz com que não só a leitura seja mais rápida, mas também confere um ritmo mais frenético aos eventos mostrados. Analisando uma página de Batman, ele mostra que

a presença dos diálogos em cada vinheta aumentaria o tempo de leitura, faria com que dedicássemos mais tempo a cada vinheta e à sequência em seu conjunto. E o efeito seria o de uma agitação muito menor, e uma maior extensão do tempo dos eventos que estão sendo mostrados. (BARBIERI, 2017, p. 217).

Conclui-se que, mesmo nas HQs mais simples, o diálogo deve ser observado não só em seu conteúdo, como também em sua forma. Em termos de tradução, o desafio imposto ao tradutor é o de compor diálogos que pareçam língua falada, caibam no balão e preservem as funções pragmáticas e de ritmo do original.

Portanto, apesar de propormos as HQs como modelo de tradução de diálogos na literatura, é preciso ter em vista as diferenças entre as duas linguagens. Todavia, como o tradutor de HQs acaba por ter mais restrições, é mais fácil para o tradutor literário tirar ideias de outra linguagem para mobilizá-las em seu trabalho.

\section{A linguagem das HQs no Brasil}

Ramos (2012) aponta três estudos que mostram uma tendência na linguagem do texto das HQs no Brasil. O primeiro, de Pretti, publicado em 1973, analisou 37 revistas de Mônica, de Maurício de Souza. Sua conclusão, segundo Ramos, foi que "apesar de identificar vários níveis de fala distintos [...] predominava o formal, próximo à variante culta.” (RAMOS, 2012, p. 61):

[O]s códigos morais pelos quais se pauta a atividade das editoras, os quais, atuando no sentido de transformar as revistas em quadrinhos em instrumento de educação coletiva, transferem essa intenção também para o plano da língua, preservando com zelo a ortografia oficial e nivelando a fala das personagens pela norma culta, o que impede, frequentemente, qualquer identificação mais precisa dos níveis sociolinguísticos. (PRETTI apud RAMOS, 2012, p. 61).

Isso trazia algumas dissonâncias, como as falas das crianças, que eram mais adequadas a "um adulto, por causa do nível de fala mais formal." (RAMOS, 2012, p. 61). Pretti publicou 
um outro estudo em 2003 em que, apesar de não mencionar especificamente as HQs, "afirma que os meios de comunicação de massa são uma rica fonte de pesquisas de fala espontânea", pois os escritores se esforçavam para "representar a fala dos personagens nos diálogos da maneira mais realista possível.” Ramos defende que isso se aplica às HQs atuais.

O terceiro estudo também analisa o nível de fala das HQs, desta vez uma HQ traduzida. Lauand (2016) ${ }^{10}$ comparou cinco traduções de uma mesma história de Tio Patinhas, publicadas em 1958, 1967, 1982, 1988 e 2004. No nível lexical, Lauand mostra que "a tendência geral é a de edições mais antigas apresentarem palavras mais cultas" (LAUAND, 2016, p. 334). Também foi identificada a mudança gradual do futuro sintético para o analítico, mais comum na língua falada.

Ou seja, sugere-se que tanto as traduções quanto os textos escritos originalmente em português convergem na tendência a falas mais oralizadas e informais.

\section{A Turma da Mônica, um modelo para a tradução}

Tendo em vista que os diálogos na ficção, segundo Britto, são representação da fala, que os balões das HQs têm essa mesma função, e que as falas nas HQs brasileiras tendem a reproduzir a oralidade, é fácil perceber como os balões podem servir de modelo prático para as propostas de Britto. E é fortuito que tenhamos HQs de ampla circulação e aceitação, com linguagem oralizada e, principalmente, voltadas para o público infantojuvenil, como as revistas e tirinhas da Turma da Mônica.

De fato, as características de oralidade apontadas por Britto não são difíceis de encontrar nessas HQs. Em uma história consultada, encontramos o uso do pronome reto no lugar do oblíquo ("Joguem ele") e uma contração e uma marca fonética ("peraí", falado ao modo de Cebolinha) na figura 6:

Figura 6

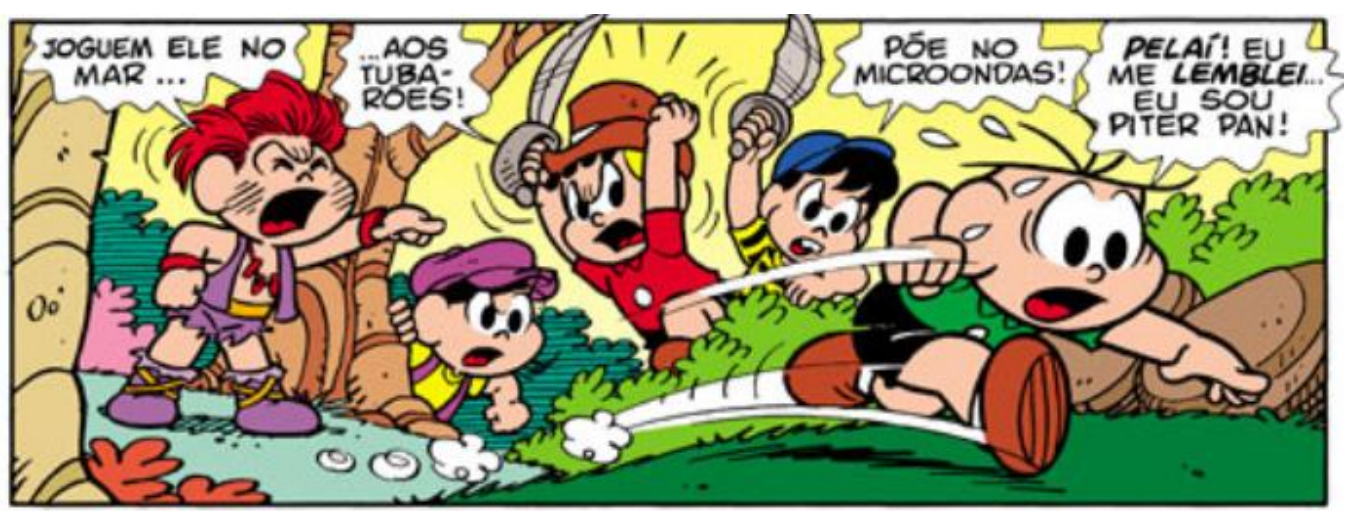

Fonte: Turma da Mônica (sem data) 
Há também o uso de artigo antes de nomes próprios ("o Piter") na figura 7 e o "pra" mencionado por Britto na figura 8:

Figura 7

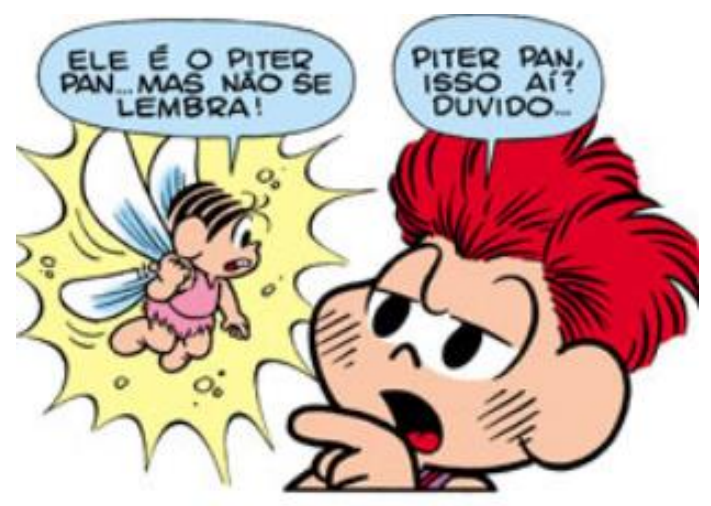

Fonte: Turma da Mônica (sem data)

Figura 8

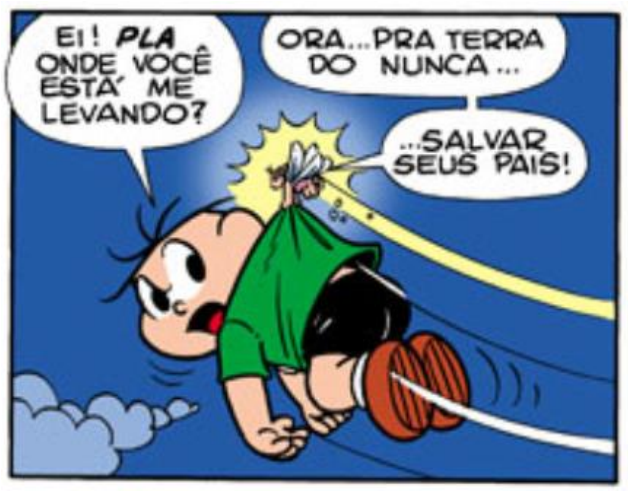

Fonte: Turma da Mônica (sem data)

Não faltam coloquialismos, como "ué" e "cadê", e contrações como "tá", que se vêem na figura 9:

Figura 9
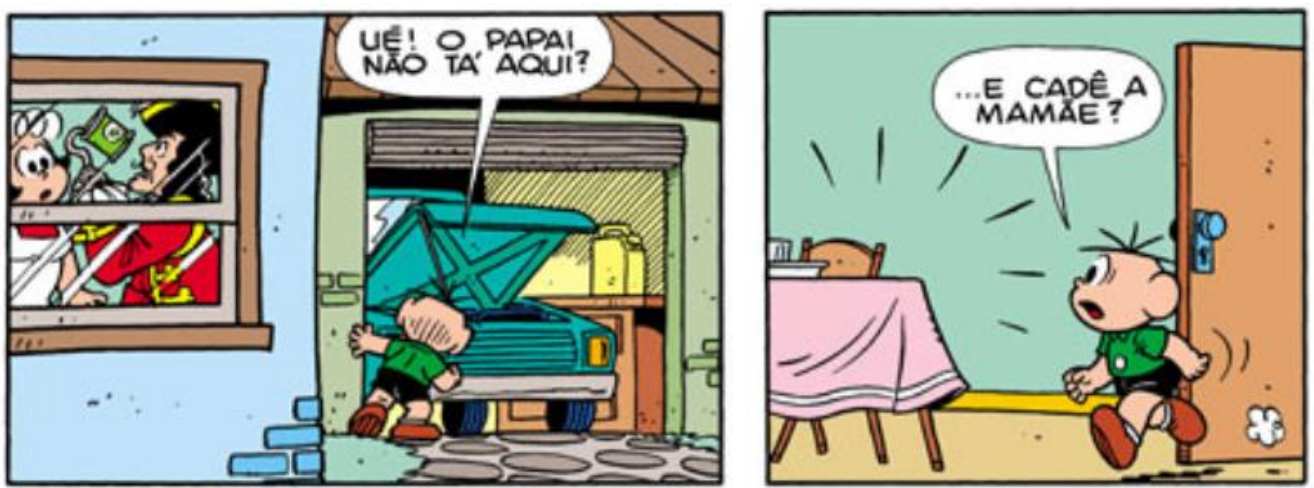

Fonte: Turma da Mônica (sem data)

BRUNETTI, Gustavo H. S. Do balão para a linha: as histórias em quadrinhos como modelo de tradução do diálogo na literatura infantojuvenil. Belas Infiéis, Brasília, v. 8, n. 3, p. 59-72, 2019. 
Vale ressaltar que o próprio Britto confessa que lhe falta ousadia para usar marcas como “tá” e "peraí", que na Turma da Mônica, entretanto, são usadas normalmente.

\section{Considerações finais}

A fim de reforçar a autonomia de sua área acadêmica, os estudiosos de HQs têm se afastado cada vez mais da comparação com a literatura, ainda que o mercado se aproveite da aproximação entre as duas áreas. Por outro lado, o estudioso da tradução pode se privar de um grande corpus se desconsiderar o que é feito hoje nas HQs.

As ideias de Britto apresentadas coincidem em muito com o que já é produzido para o público infantojuvenil pela Turma da Mônica, e, assim, estas se mostram um exemplo válido para o que aquelas propõem.

Talvez, usando-se esse modelo, atinja-se maior naturalidade na literatura infantojuvenil. Para isso, pode ser necessária ousadia por parte dos tradutores, mas, no futuro, seria uma boa surpresa se os leitores encontrarem um Hucleberry Finn que fale não como Jânio Quadros, mas como Chico Bento.

\section{REFERÊNCIAS BIBLIOGRÁFICAS}

ASSIS, Érico Gonçalves de. Especificidades da tradução de histórias em quadrinhos: abordagem inicial. Tradterm, São Paulo, v. 27, p. 15-37, out 2016. Disponível em: http://www.revistas.usp.br/tradterm/article/view/121369 Acesso em: 15 jun. 2019.

BARBIERI, Daniele. As linguagens dos quadrinhos. Traduzido por: Thiago de Almeida Castor do Amaral. São Paulo: Peirópolis, 2017.

BRITTO, Paulo Henriques. A tradução literária. Rio de Janeiro: Civilização Brasileira, 2012.

DITKO, Steven; LEE, Stan. Amazing Spider-Man \#13. New York: Marvel, 1964.

EISNER, Will. Comics \& sequential art. Tamarac: Poorhouse Press, 1985.

GROSSMAN, Lev; LACAYO, Richard. All-time 100 novels. Time: 2005. Disponível em: http://entertainment.time.com/2005/10/16/all-time-100-novels/slide/all/ Acesso em: 15 jun. 2019.

GUREWITCH, Nicholas. Amends. Sem data. Disponível em: http://pbfcomics.com/comics/amends/. Acesso em: 15 jun. 2019.

GUREWITCH, Nicholas. Bee. Sem data. Disponível em: http://pbfcomics.com/comics/bee/. Acesso em: 15 jun. 2019. 
LAUAND, Jean. O laboratório de tio Patinhas - as mudanças de linguagem de cada geração. Revelando a linguagem. São Paulo: Factash Editora, 2016. Disponível em: http://www.jeanlauand.com/RevelandoaLingPort.pdf. Acesso em: 15 jun. 2019.

MCCLOUD, Scott. Understanding comics: The invisible art. New York: Harper Collins, 1994.

RAMOS, Paulo. A leitura dos quadrinhos. São Paulo: Contexto, 2012.

TOMÁŠEK, Ondřej. Translating Comics. Dissertação de Mestrado, Masaryk University, 2009. Disponível em: http://is.muni.cz/th/146660/ff_m/Thesis_-_final.pdf. Acesso em: 15 jun. 2019.

TURMA DA MÔNICA. Clássicos do cinema - Comandante Gancho. Sem data. Disponível em: http://turmadamonica.uol.com.br/historia/classicos-do-cinema-comandante-gancho-7/ cesso em: 16 jun. 2019.

WEINERSMITH, Zachary. Sem título. 2018. Disponível em: http://smbccomics.com/comic/the-best. Acesso em: 16 jun. 2019.

\footnotetext{
* Gustavo Henrique Santos BRUNETTI - Mestrando em Estudos da Tradução na Universidade de São Paulo. Graduado em Letras - Português/Francês (2009) pela Universidade de São Paulo. Especialista em Tradução pelo Centro Universitário Anhanguera. É professor do Centro Universitário das Faculdades Metropolitanas Unidas. São Paulo, São Paulo, Brasil.

Currículo acadêmico: http://lattes.cnpq.br/4454603956732848

ORCID: https://orcid.org/0000-0001-9630-2430

E-mail: gustavo.brunetti@usp.br

${ }^{1}$ Utilizarei neste artigo o termo "HQs" para me referir à linguagem e "vinheta" para me referir ao que há "dentro de um conjunto de linhas, formando um retângulo, quadrado, esfera ou outro formato" (RAMOS, 2012, p. 89) e também essas linhas.

${ }^{2} \mathrm{O}$ próprio nome graphic novel, que literalmente significa "romance gráfico", denota a tentativa de associar as HQs com a literatura. Também explica a inclusão de uma graphic novel na lista que será citada na próxima frase.

${ }^{3}$ Ramos aqui classifica as HQs como uma linguagem, ao passo que na mesma obra, adiante, na página 20, classifica-as como hipergênero, emprestando a terminologia de Maingueneau. Neste trabalho, seguiremos as concepções de Barbieri (2017), que entende as HQs inequivocamente como linguagem.
}

4 "Our eyes have well-trained by the photograph and by representational art to see any continuous image as a single instant in time." Todas as traduções são nossas.

5 "If sound is introduced, this ceases to be true".

6 "In writing words alone, the author directs the reader's imagination. In comics the imagining is done for the reader. An image once drawn becomes a precise statement that brooks little or no further interpretation. When the two are 'mixed' the words become welded to the image and no longer serve to describe but rather to provide sound, dialogue and connective passages."

${ }^{7}$ Como há HQs que não apresentam palavras, tendemos a concordar com Eisner; por outro lado, a imensa maioria das HQs se vale de palavras, o que nos faz considerar que o normal dessa linguagem é o uso dos dois elementos, e o uso de apenas imagens seria exceção.

8 “(...) literature, unlike comics, does not contain untranslatable units (...) and there are no limitations that would hold the translator down from modifying the text. On the other hand, translator of comics is limited by the size of the caption or word balloon (they can be modified in order to accommodate (sic) the text, but the modification can be performed only to some extent, otherwise, the balloon or the caption would blot out the images)." Tradução nossa. 
${ }^{9}$ Existem discussões a respeito de narrações e outros textos geralmente inseridos nos recordatórios, também chamados de legendas. Por quase sempre representarem a voz narrador (onisciente ou não, segundo Ramos, 2012, p. 50), esses textos podem assumir a forma de língua escrita.

${ }^{10} \mathrm{O}$ texto a que tivemos acesso, apesar de estar em uma coletânea de 2016, foi originalmente publicado na revista Língua Portuguesa em 2006. 